\author{
赤色面発光レーザー \\ 波多腰玄一, 高岡 圭児 \\ (株) 東芝研究開発センター 個別半導体基盤技術ラボラトリー（テ212-8582 川崎市幸区小向東芝町1）
}

\title{
Red VCSELS
}

Gen-ichi HATAKOSHI and Keiji TAKAOKA

Advanced Discrete Semiconductor Technology Laboratory, Corporate Research \& Development Center, Toshiba Corporation, 1 Komukai Toshiba-cho, Saiwai-ku, Kawasaki 212-8582

(Received June 11, 2001)

\begin{abstract}
Red-light surface-emitting lasers are expected to be applied as compact light sources for optical data links employing plastic optical fibers. InGaAlP red VCSELs have been successfully fabricated. One of the important subjects respecting InGaAlP VCSELs is improvement in temperature characteristics. Reduction of the active region diameter is advantageous in that threshold current is reduced, resulting in a reduction of heat generation. It is also effective for the reduction of thermal resistance, due to the heat dissipation through the upper and side regions. The control of such transverse structure is very important for obtaining high-performance VCSELs. Excellent temperature characteristics were obtained for 666-nm VCSELs with a protonimplanted planar structure.
\end{abstract}

Key Words: VCSEL, Vertical-cavity surface-emitting laser, InGaAlP, POF data link

\section{1.まえがき}

面発光レーザー1-3) は, 低しきい值動作, 高い電力/光変換 効率, 円形の狭広がり角出射光, 実装が容易, 2次元集積化 が可能等の優れた特長があり, 光情報処理や光伝送の分野 で様々な応用の可能性がある。可視域の $0.6 \mu \mathrm{m}$ 帯で発振す る赤色面発光レーザーは, プラスチック光ファイバ $(\mathrm{POF})$ を用いた光データリンク, 光メモリ, レーザープリンター 等の光源として期待されている. 特にPMMA系POFの低損 失領域が赤色であることから, POFデータリンク用光源と しての期待は高い。これまでにInGaAlP材料を用いた垂直 共振器型面発光レーザー(VCSEL)では, 630〜 690nmでの発 振が報告されている4-12)，VCSELは活性層体積が極めて小 さいために低しきい值化が可能であるが,一方高出力化や 高温発振は端面発光型に比べると容易ではない．特に InGaAlP系では材料の熱抵抗やキャリアオーバーフロー等 の影響が大きく, 温度特性の確保は重要な課題の一つであ る.

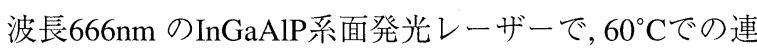
続発振が達成された。高速変調が可能であり, POFデー夕 リンク用光源に適用可能であることが確認できた12-17)。広 がり角の小さい円形出射ビームの得られる赤色面発光 レーザーはPOFへの光結合も容易であり，低価格の高速 データリンクに適した光源である．以下では赤色VCSEL の構造設計, 素子特性について述べる.
2. 赤色面発光レーザーの構造と諸特性

面発光レーザーの電流狭窄構造としては, 選択酸化型お よびプロトン注入型が一般に用いられている。我々は両 者の構造のInGaAIP系VCSELを試作し,いずれの構造にお いても50 $\mathrm{C}$ 以上での連続発振の実現に成功した ${ }^{12-14)}$ 。プ ロトン注入型赤色VCSELの構造例をFig.1に示す。後述す るように, 図に示した電流注入径Dは素子特性に大きく影 響するパラメータである。

共振器を構成する分布ブラッグ反射鏡 $(\mathrm{DBR})$ には各光 学膜厚が四分の一波長の $\mathrm{Ga}_{0.5} \mathrm{Al}_{0.5} \mathrm{As} / \mathrm{Ga}_{0.05} \mathrm{Al}_{0.95} \mathrm{As}$ 多層膜 を用いている。面発光レーザーで必要な高反射率を確保 するために, n 側, p側とも数十対の多層膜となるため, 各へ

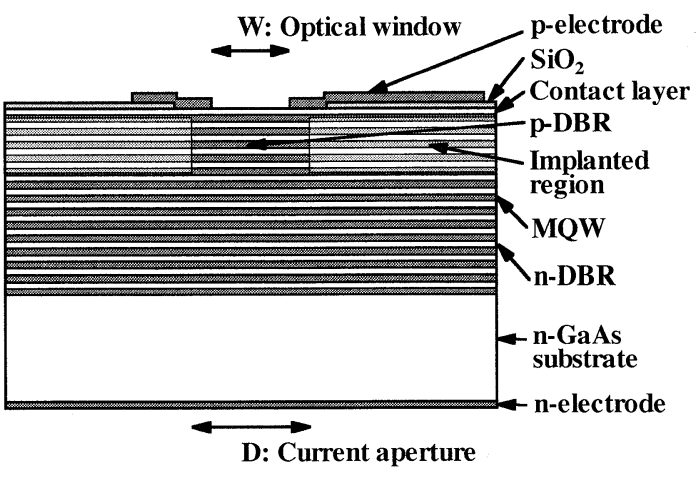

Fig.1 Configuration of proton-implanted red VCSEL. 
テロ界面のわずかな電圧降下が全体では大きな素子抵抗 の原因となる。この電圧降下を低減するため, 多層膜界面 には組成を連続的に変化させたグレーデッド層を設けて ある。Fig.2はグレーデッド層の効果を計算機シミュレー ションにより定性的に示したものである。急峻な界面の 場合には, n-DBR, p-DBRいずれの場合もへテロ障壁高さが 人きく, 電流引゙流れ難いのに対し, 少レーデッド層を設け た界面では容易に電子電流, 正孔電流が流れることがわか る。この効果は特にp-DBRで顕著である。

実際に試作した素子の電流一電圧特性をFig.3に示す. 電流注入径Dが小さい程素子抵抗は大きくなり, $\mathrm{D}=10 \mu \mathrm{m}$ の素子では微分抵抗の值は $100 \Omega$ 以上であるが, 電流注入面 積と微分抵抗との積としては, 従来のLEDと同じオーダー
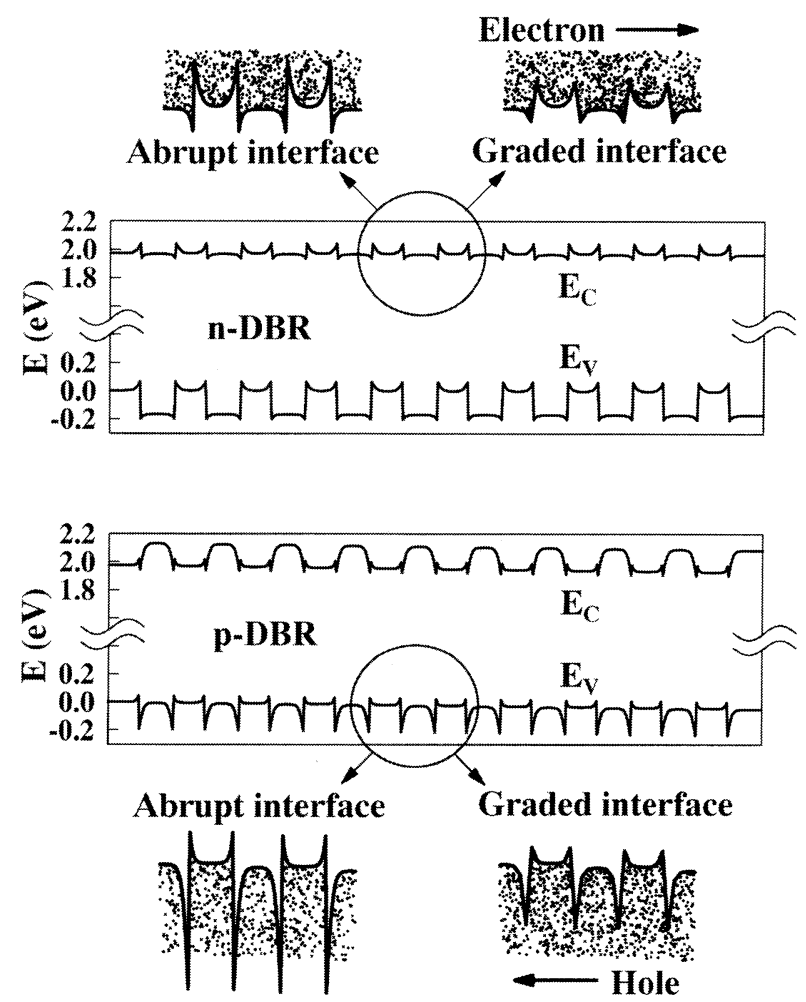

Fig.2 Simulation example for the effect of graded layer at the DBR interfaces.

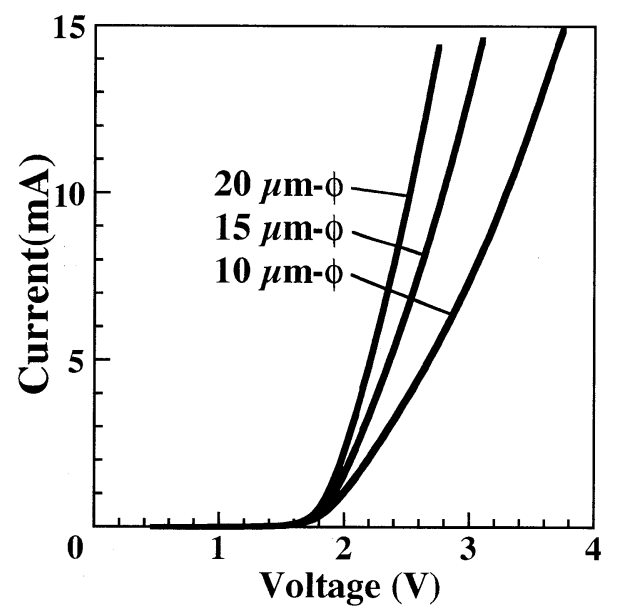

Fig.3 Measured current-voltage characteristics of red VCSELS.
の值が得られており,グレーデッド層の効果が現れている と考えられる。

測定された発振スペクトルおよび遠視野像強度分布の例 をそれぞれFig.4およびFig.5に示す。遠視野像広がり角の半 值幅は6.6 と小さく, また図のように円形の出射ビームが得 られている。このような出射光は, コア系の大きいプラス チックファイバーに容易に結合させることができる。

赤色VCSELの高速変調特性をFig.6に示す。この図は1.2 Gbpsの擬似ランダム信号で変調した場合のアイパターン の測定結果で, 測定系が必ずしも最適化されてはいないが, $1 \mathrm{Gbps}$ 以上での高速変調が可能といえる.

3. 赤色面発光レーザーの温度特性

最初に述べたように, 赤色VCSELでは温度特性が重要課 題の一つであるので,ここで少し詳しく述べる，連続発振

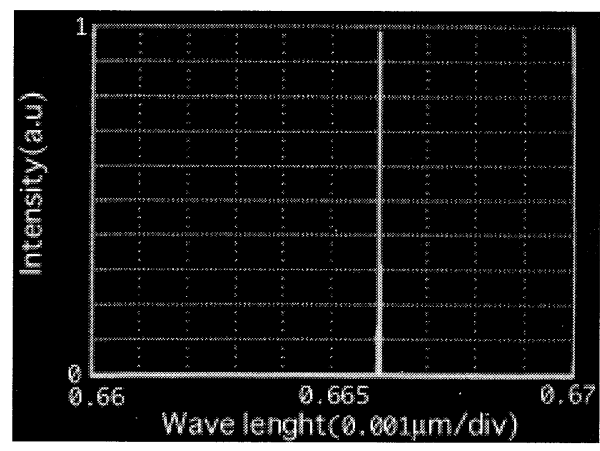

Fig.4 Oscillation spectrum.

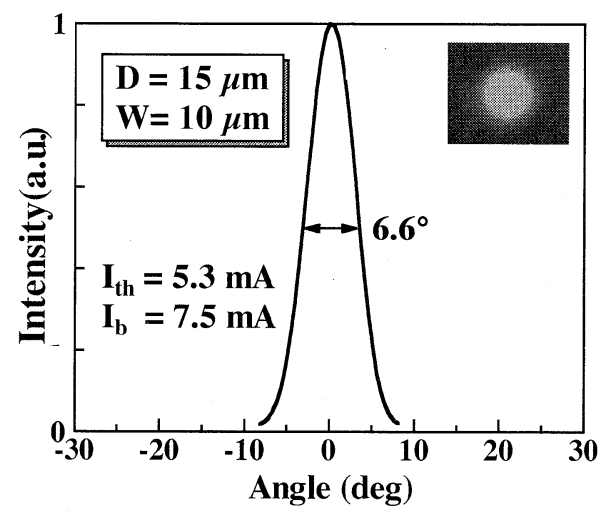

Fig.5 Measured far field profile for the output beam of red VCSEL.

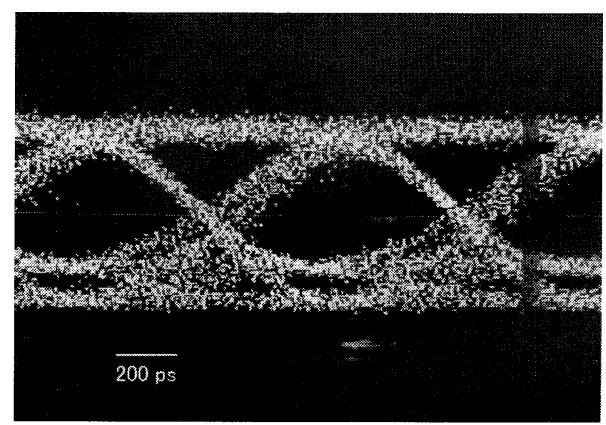

Fig.6 Measured eye pattern for red VCSEL driven at 1.2 Gbps NRZ signal. 
時における電流一光出力特性の温度依存性をFig.7に示 す，図からわかるように, 温度特性は電流注入領域の径D に大きく依存している。Dが10 $\mu \mathrm{m}$ の素子では発振しきい

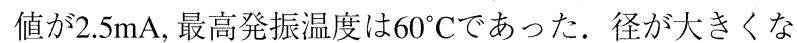
ると共にしきい值は上昇し, 最高発振温度は低くなる。室 温でのしきい值としきい電流密度の電流注入領域面積 $\mathrm{S}$ に 対する依存性をFig.8に示す。電流密度は, 面積の小さい領 域では電流広がりと導波損失により，また面積の大きい領 域では電流注入不均一にそれぞれ起因して若干増加して いるが, 約 $2 \mathrm{kA} / \mathrm{cm}^{2}$ の值でほぼ一定である。このため, し きい值は電流注入面積にほほ比例している。

Fig.7に示した温度特性の電流注入径Dに対する依存性を Fig.9およびFig.10に示す．Fig.10からわかるように, 最高発 振温度 $\mathrm{T}_{\max }$ は電流注入径Dが小さくなるにつれて, ほぼ線
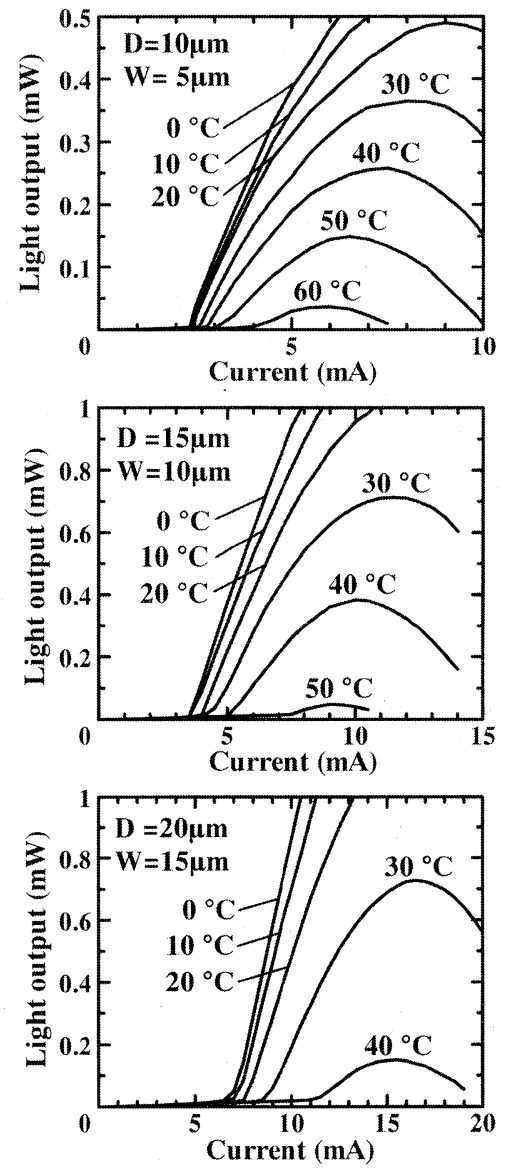

Fig.7 Temperature dependence of I-L characteristics.

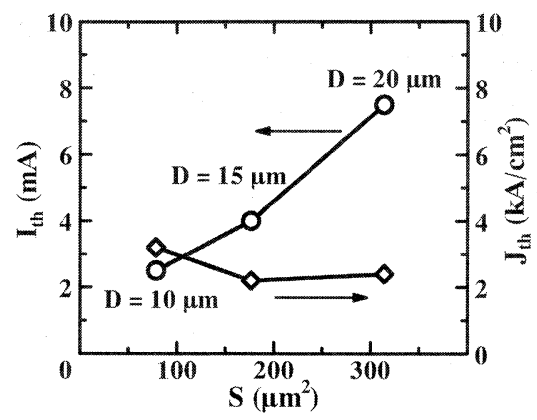

Fig.8 Threshold current and threshold current density as a function of current aperture area.
形に増加している。このような特性と, 素子の熱抵抗およ び発振しきい值との間には大きな相関がある。したがっ て, VCSELではしきい值を低減する構造設計と共に, 熱抵 抗低減のための設計が特に重要である.

プロトン注入型赤色VCSELにおける電流分布および熱 流分布の計算機シミュレーション例16)をFig.11に示す。 上 述のように面発光レーザーでは, 電流注入領域の大きさが デバイス特性に影響する重要なパラメータである。基本 モード発振には活性層の電流注入領域を小さくする必要 があるが,これは同時に熱流の広がりによる熱抵抗低減の 効果があり (Fig.11（b)），素子の温度特性にも大きく影響す 万.

熱流の広がりの効果 ${ }^{17)} に$ 関するシミュレーション結果 をFig.12に示す.Fig.12(a)のように発光領域(発熱源)が小 さい場合は熱が活性層領域の横および上の領域にも広 がってヒートシンクへ流れるのに対し, Fig.12(b)のように 発光領域面積が大きい場合にはその効果は小さい.

熱の流れが1次元的にヒートシンクへ流れるとすると, 熱 抵抗は熱源面積に反比例することになるが, Fig.13に示し たように, 計算機シミュレーションによると, 熱抵抗は熱 源面積ではなく, 熱源の直径(すなわち面積の平方根)にほ ぼ比例することがわかった。これは上述したように熱 源面積が小さい程, 熱広がりの効果が大きいためである. 一方, Fig.8に示したように発振しきい值は面積にほぼ比例 しているので, 発生する熱は発光面積に比例すると考えら れる。したがって, 発生熱×熱抵抗で与えられる活性層温 度上昇は発光面積径に比例することになり,これはシミュ レーションでも確認された(Fig.14). Fig.10に示した最高 発振温度の電流注入径に対する依存性は, このメカニズム

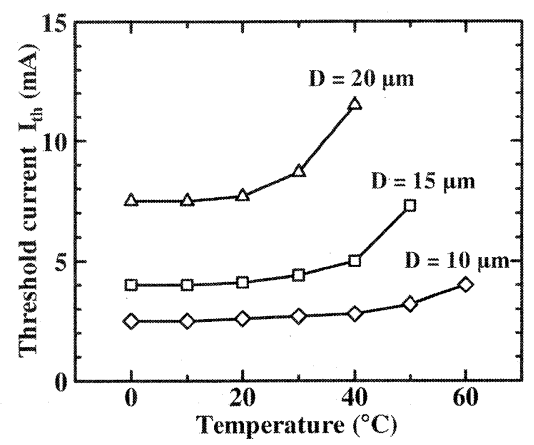

Fig.9 Temperature dependence of the threshold current.

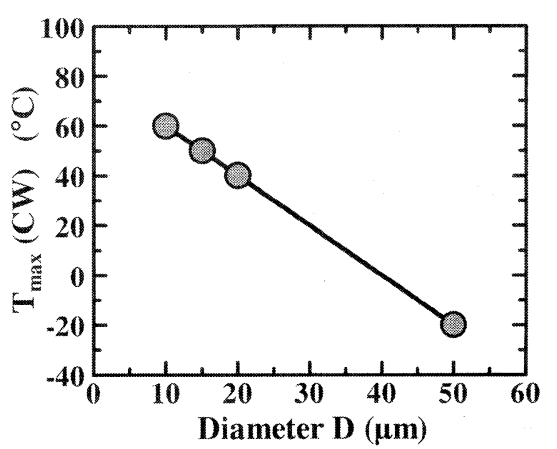

Fig.10 Maximum CW temperature as a function of current aperture size. 


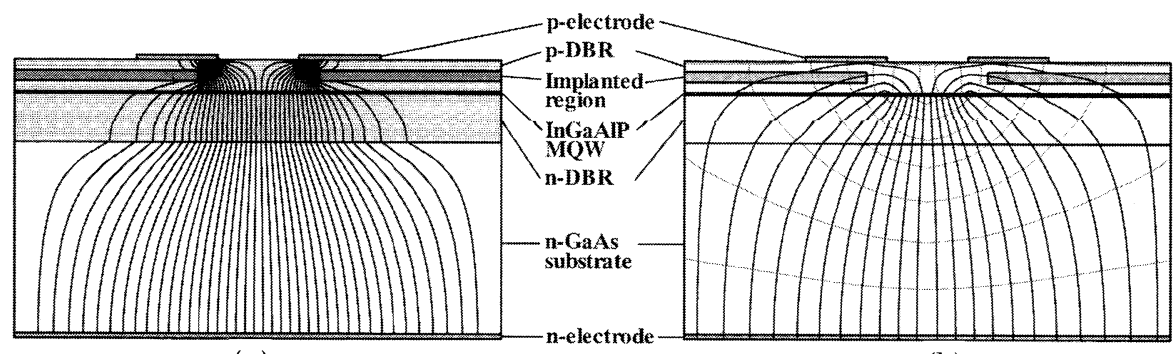

(a)

(b)

Fig.11 Calculated examples for current distribution (a) and heat flow (b) in proton-implanted VCSEL.

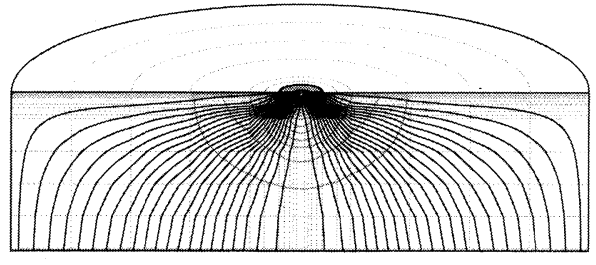

(a)

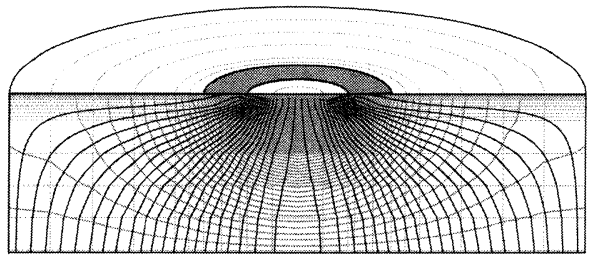

(b)

Fig.12 Heat flow simulation for InGaAlP red VCSELs. (a) Small heat generation area. (b) Large heat generation area.

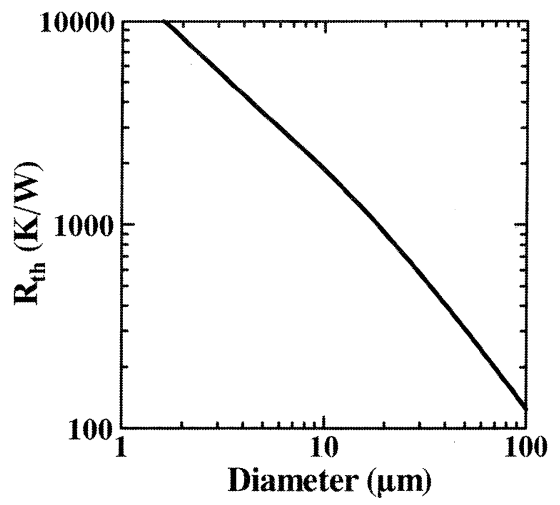

Fig.13 Calculated thermal resistance as a function of diameter D.

を反映しているものと考えられる。

\section{4. あとがき}

InGaAlP系材料を用いた赤色面発光レーザーの構造設計 と特性について述べた。構造が簡単な平板型プロトン注 入電流狭窄構造VCSELで, 波長 $666 \mathrm{~nm}$ において, しきい值 $2.5 \mathrm{~mA}$, 最高発振温度 $60^{\circ} \mathrm{C}$ が得られた。さらなる温度特性 向上に向けたデバイス設計では, 低しきい值化, 熱抵抗低 減が特に重要である。半導体レーザーとしての高性能特 性と, LED と同様の実装容易性を兼ね備えた赤色面発光 レーザーは, 低価格・高速データリンク用光源として有望

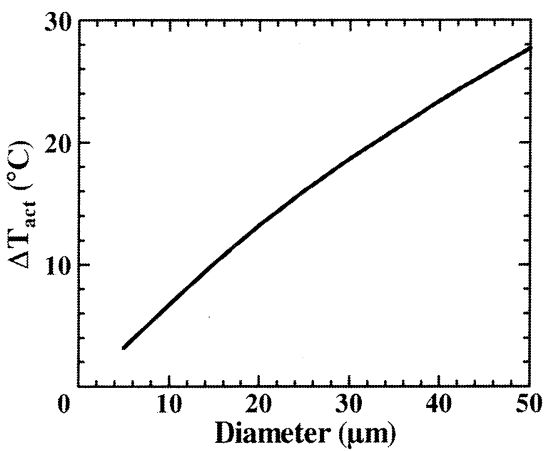

Fig.14 Calculated temperature rise in the active layer.

なデバイスである。

\section{参考文献}

1) K. Iga, F. Koyama, and S. Kinoshita: IEEE J. Quantum Electron. 24 (1988) 1845.

2）伊賀 健一, 小山二三夫：電子情報通信学会誌 80 (1997) 687.

3) K. D. Choquette and H. Q. Hou: Proc. IEEE 85 (1997) p.1730.

4) J. A. Lott and R.P. Schneider, Jr.: Electron. Lett. 29 (1993) 830.

5) K. Tai, K.F. Huang, C. C. Wu, and J. D. Wynn: Electron. Lett. 29 (1993) 1314.

6) R. P. Schneider, Jr., K. D. Choquette, J. A. Lott, K. L. Lear, J. J. Figiel, and K. J. Malloy: IEEE Photonics Tech. Lett. 6 (1994) 313.

7) K. D. Choquette, R. P. Schneider, M. H. Crawford, K. M. Geib, and J. J. Figiel: Electron. Lett. 31 (1995) 1145.

8) M. H. Crawford, R. P. Schneider, Jr., K. D. Choquette, and K. L. Lear: IEEE Photonics Tech. Lett. 7 (1995) 724.

9) Y. H. Chen, J. Woodhead, J. P. R. David, C. C. Button, M. Hopkinson, J. S. Roberts, T. E. Sale, and P. N. Robson: Mat. Sci. Eng. B35 (1995) 12.

10) J. A. Lehman, R. A. Morgan, D. Carlson, M. H. Crawford, and K. D. Choquette: Electron. Lett. 33 (1997) 298.

11) R. Stevens, R. Marcks Von Wurtemberg, R. Schatz, and K. Streubel: Proc. Int. POF Conf'99 (Makuhari Messe, Chiba, 1999) paper PJ4.

12) K. Takaoka, H. Furuyama, M. Ishikawa, G. Hatakoshi, H. Saito, M. Sugizaki, and H. Tamura: Proc. Int. POF Conf. '99 (Makuhari Messe, Chiba, 1999) paper PPD4.

13) K. Takaoka, M. Ishikawa, and G. Hatakoshi: Proc. APCC/OECC'99 (Beijing, 1999) paper PD-2.

14) K. Takaoka, M. Ishikawa, and G. Hatakoshi: Proc. OECC2000 (Makuhari Messe, Chiba, 2000) paper 14C2-5.

15) K. Takaoka, M. Ishikawa, and G. Hatakoshi: Conf. Digest, 2000 IEEE 17th International Semiconductor Laser Conf. (Monterey, 2000) paper p.15.

16) G. Hatakoshi, K. Takaoka, and M. Ishikawa: Proc. IEEE/LEOS 2000 Annual Meeting (Rio Grande, 2000) paper ThF1.

17）波多腰玄一, 高岡 圭児：レーザー学会学術講演会第21回年次 大会講演予稿集 (2001) 208. 